\title{
Disturbance alters local-regional richness relationships in Appalachian forests
}

\author{
R. Travis Belote, ${ }^{1,3}$ Nathan J. Sanders, ${ }^{2}$ and Robert H. Jones ${ }^{1}$ \\ ${ }^{1}$ Department of Biological Sciences, Virginia Tech, Blacksburg, Virginia 24061 USA \\ ${ }^{2}$ Department of Ecology and Evolutionary Biology, University of Tennessee, Knoxville, Tennessee 37996 USA
}

\begin{abstract}
Whether biological diversity within communities is limited by local interactions or regional species pools remains an important question in ecology. In this paper, we investigate how an experimentally applied tree-harvesting disturbance gradient influenced local-regional richness relationships. Plant species richness was measured at three spatial scales ( $2 \mathrm{ha}=$ regional; $576 \mathrm{~m}^{2}$ and $1 \mathrm{~m}^{2}=$ local) on three occasions (one year pre-disturbance, one year post-disturbance, and 10 years post-disturbance) across five disturbance treatments (uncut control through clearcut) replicated throughout the southern Appalachian Mountains, USA. We investigated whether species richness in $576-\mathrm{m}^{2}$ plots and $1-\mathrm{m}^{2}$ subplots depended on species richness in 2-ha experimental units and whether this relationship changed through time before and after canopy disturbance. We found that, before disturbance, the relationship between local and regional richness was weak or nonexistent. One year after disturbance local richness was a positive function of regional richness, because local sites were colonized from the regional species pool. Ten years after disturbance, the positive relationship persisted, but the slope had decreased by half. These results suggest that disturbance can set the stage for strong influences of regional species pools on local community assembly in temperate forests. However, as time since disturbance increases, local controls on community assembly decouple the relationships between regional and local diversity.
\end{abstract}

Key words: Appalachian Mountains; disturbance; forest management; local-regional richness relationships; spatial scale; species richness; succession.

\section{INTRODUCTION}

Understanding the relative influence of regional and local processes on local community diversity may help explain why biological diversity varies across habitats and through time (Shurin and Srivastava 2005, Harrison and Cornell 2008). In particular, local-regional richness relationships (LRRs) have become a popular means for exploring whether local diversity is more strongly limited by regional species pools or by local interactions (Fig. 1; Harrison and Cornell 2008). Saturating LRRs are often interpreted as an indication that strong local interactions limit the number of species within local communities (Cornell and Lawton 1992). In contrast, linear LRRs are interpreted as evidence that local diversity is not limited by local interactions but by the regional species pool (Caley and Schluter 1997; sensu Stohlgren et al. 2008). Investigations of LRRs have been

Manuscript received 13 October 2008; revised 9 January 2009; accepted 13 January 2009. Corresponding Editor: T. J. Stohlgren.

${ }^{3}$ Present address: U.S. Geological Survey, Southwest Biological Science Center, Flagstaff, Arizona 86011 USA. E-mail: rtbelote@vt.edu criticized for a number of reasons including statistical limitations of studies and because mechanisms other than species interactions may influence LRRs (Huston 1999, Srivastava 1999, Loreau 2000, Hillebrand and Blenckner 2002, Hillebrand 2005). Nonetheless, investigating LRRs remains a common approach for elucidating the extent to which local and regional processes might shape local communities, especially when the assumptions and shortcomings are made explicit.

Disturbance is widely recognized as an important process that influences diversity and composition of communities across both spatial (Collins et al. 2002) and temporal scales (Mouquet et al. 2003). Increased resource availability and decreased resource uptake immediately following disturbance can reduce potential competitive exclusion by dominant species at local scales and allow habitats to be colonized by species adapted to disturbed environments (Huston 1999). At regional scales, disturbance can increase environmental heterogeneity and landscape-level diversity (Foster et al. 1998). Thus, disturbance likely alters LRRs by influencing diversity across spatial scales, as well as interactions among species at local spatial scales. However, the 
extent to which disturbance modifies LRRs has been little examined.

Mouquet et al. (2003) developed a simulation model to investigate local-regional richness relationships through time during community assembly. Their model predicted that LRRs would change through time reflecting the influence of colonization during initial establishment and competition as the community reached equilibrium (Fig. 1). In one of the only experimental studies to date that tested this model, Starzomski et al. (2008) found no relationship between regional diversity and local diversity during community assembly of microarthropods in moss patches. No studies, to our knowledge, have investigated LRRs through time after experimentally disturbing natural systems across a range of disturbance intensities.

In this paper, we use data from an ongoing experiment in forests of the southern Appalachian Mountains to investigate whether disturbance alters LRRs of vascular plant species. An overall goal of the experiment is to investigate how disturbance caused by timber harvesting influences vascular plant diversity through time and across spatial scales ranging from 2 ha to $1 \mathrm{~m}^{2}$. The disturbance treatments represent a gradient of canopy removal and associated forest floor disturbance created by different levels of tree harvesting (Belote et al. 2008). These forest sites have been sampled periodically, allowing the opportunity to examine LRRs over a $10-y r$ period following disturbance. We tested three specific predictions about the effects of disturbance on LRRs based on simulation and conceptual models (Mouquet et al. 2003; Fig. 1). First, we predicted that before disturbance LRRs would be asymptotic, suggesting limits to sampled individuals (sensu Loreau 2000) or species saturation in small scale plots $\left(576 \mathrm{~m}^{2}\right.$ and $\left.1 \mathrm{~m}^{2}\right)$. Second, we predicted that after disturbance LRRs would become linear and the community unsaturated via colonization of new species (Belote et al. 2008). Third, we predicted that LRRs would change through time as local community processes intensify and prevent colonization of species from the surrounding region (Fig. 1; Mouquet et al. 2003).

\section{Methods \\ Study sites}

Seven sites (experimental blocks) were chosen in the Appalachian Mountains of southwestern Virginia and northeastern West Virginia, USA (Fig. 2; Belote et al. 2008). Sites were selected to represent similar overstory composition and age and were dominated by Quercus spp. (oaks) with other hardwood species common throughout the overstory. The understory at the sites is diverse with more than 700 native species, including a variety of understory trees (e.g., Sassafras albidum (Nutt.) Nees, Nyssa sylvatica (Marsh.)), shrubs (e.g., Rhododendron spp., Vaccinium spp.), lianas (e.g., Smilax
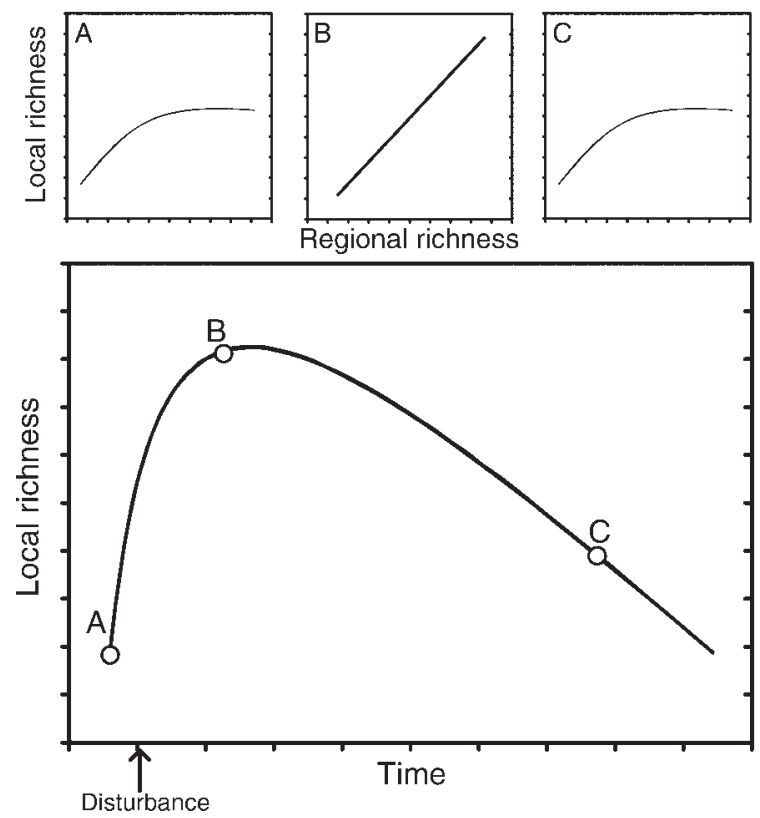

FIG. 1. Predicted diversity response of forest plant communities following canopy disturbance (after Mouquet et al. [2003] and Starzomski et al. [2008]). Each point on the curve represents a sampling period where local and regional richness relationships are assessed (shown in top panels). (A) Before disturbance, strong species interactions lead to saturating localregional richness relationships (LRR). (B) Immediately following disturbance, colonization of species leads to an unsaturated LRR. (C) After canopy closure, dominant trees once again reduce local diversity, leading to a saturating LRR.

spp.), graminoids (e.g., Carex spp., Dichanthelium spp.), and herbaceous monocots (e.g., members of Liliaceae and Orchidaceae) and dicots (e.g., species from Asteraceae and Rosaceae). Sites are located on similar topographic positions with generally south-facing, moderate slopes $(10-40 \%)$ and intermediate elevations $(600-1200 \mathrm{~m})$. Soils at all sites are rocky, well-drained, acidic, and derived from sandstone and shale residuum and colluvium. For additional information about the sites, see Hood (2001).

\section{Disturbance treatments}

At each of the seven sites, five 2-ha experimental units (EUs) were established with no buffer between units (Fig. 2). Nested within each EU, three permanent 576$\mathrm{m}^{2}(24 \times 24 \mathrm{~m})$ plots were arranged so that they were 23 $\mathrm{m}$ from the EU edge and were separated by an azimuth of $120^{\circ}$ from EU center. Six $1-\mathrm{m}^{2}$ subplots were nested within each 576- $\mathrm{m}^{2}$ plot (subplots were located along plot perimeters). Disturbance treatments were applied to the 2-ha experimental units between 1993 and 1998, during the non-growing season. Treatments were randomly assigned to EUs within each site, and included a range of overstory removal, from clearcut $(95 \%$ basal area removed), leave-tree harvest ( $74 \%$ of basal area 


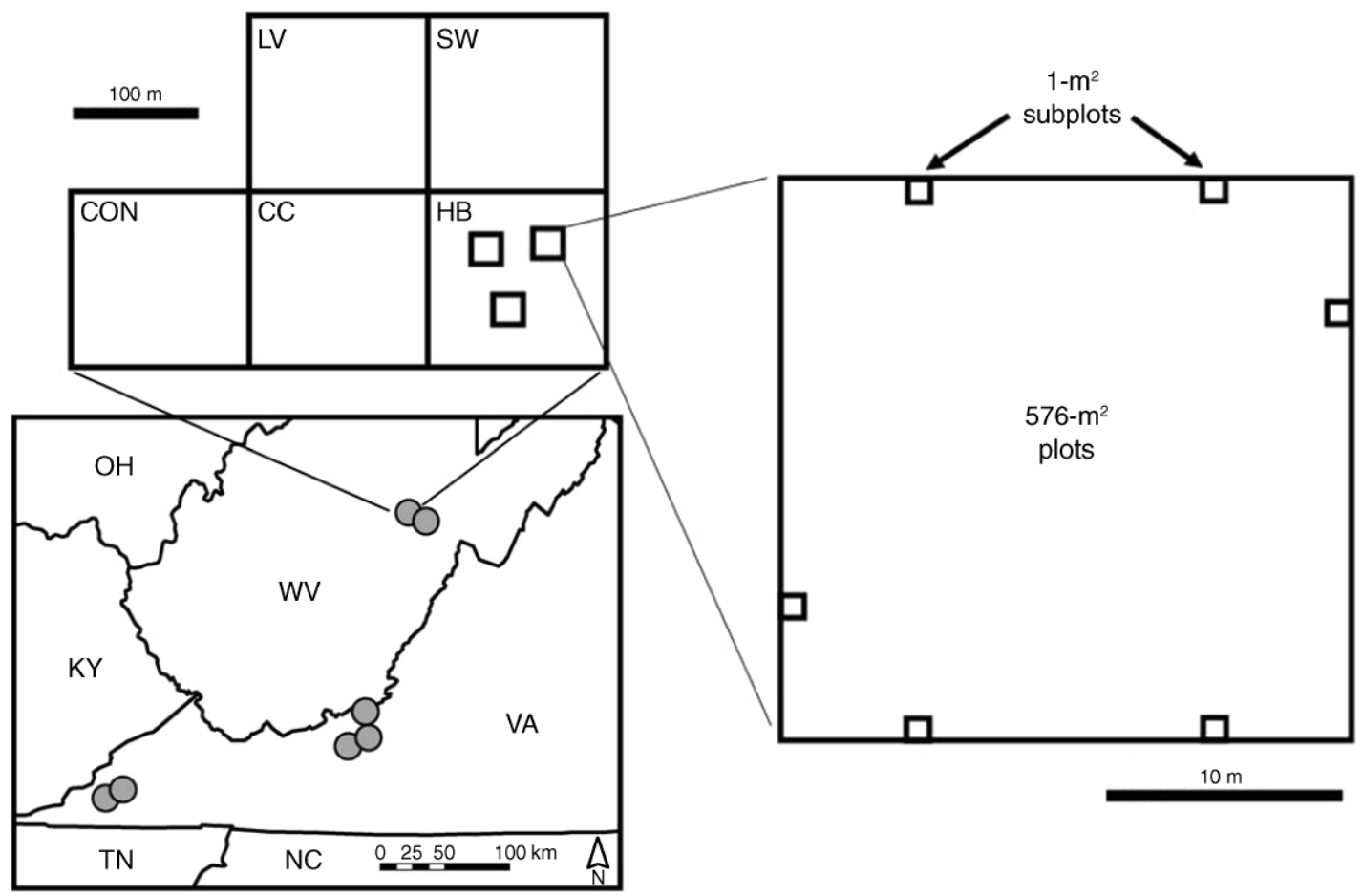

FIG. 2. Study site locations within Appalachian region of Virginia and West Virginia, USA, with site and sampling design detailed. Regional richness was considered to be richness measured at the entire 2-ha experimental unit, and local richness was measured at either the $576-\mathrm{m}^{2}$ plots or $1-\mathrm{m}^{2}$ subplots. State abbreviations are: OH, Ohio; KY, Kentucky; WV, West Virginia; VA, Virginia; TN, Tennessee; NC, North Carolina. Treatment codes are shown only as an example: $\mathrm{CON}=$ control; $\mathrm{HB}=\mathrm{herbicide}$; $\mathrm{SW}=$ shelterwood; $\mathrm{LV}=$ leave tree; $\mathrm{CC}=$ clearcut.

removed leaving a few dominants), shelterwood harvest (56\% of basal area removed), understory herbicide (removal of suppressed trees via basal application of herbicide), to uncut control. Two additional treatments were originally included in the design but were not reinventoried during the 10-year post-disturbance sampling. Control treatments were intended to represent areas that experience no disturbance related to timber harvesting. However, during treatment application of nearby sites, some disturbance associated with skid trails and diffuse light from adjacent treatments occurred within some uncut control EUs. These disturbances were mostly restricted to the edges of the EUs, but did influence species diversity in the control treatments. One West Virginia site did not include the understory herbicide treatments and we did not resample the leave-tree harvest treatment at this site; thus the experimental set-up is an unbalanced randomized block design consisting of a total of 33 EUs.

\section{Data collection}

Data were collected at three sampling times to determine how LRRs might change through time. Specifically, data were collected one year prior to disturbance treatment application with the exception of one site where pre-disturbance data were collected two years prior to harvesting disturbance (Hood 2001). Sites were resampled one or two years following disturbance and again nine to eleven years following disturbance. For all analyses we consider and refer to the initial post disturbance sampling as one year postdisturbance and the second resample as 10 -year postdisturbance. At each sampling period, presence of all herbaceous and woody plant species were recorded at each of the three scales $\left(E U=2\right.$ ha; plot $=576 \mathrm{~m}^{2}$; and subplot $=1 \mathrm{~m}^{2}$ ) and used to document species richness at each scale (Fig. 2). Richness was averaged across plots and subplots within experimental units to generate mean richness sampled at $576 \mathrm{~m}^{2}$ or $1 \mathrm{~m}^{2}$, respectively. Because our goal was to investigate the impact of disturbance on LRRs, we consider the scale at which disturbance treatments were applied (2-ha experimental units) to represent the "regional" species pool, and plots and subplots to represent local scales. These experimental units are large and contain considerable environmental variability compared to smaller plots and subplots (see Plate 1), though we recognize that other investigators often use "regional" to refer to spatial extents at much larger scales (e.g., watersheds, counties). See the Appendix for richness data. 

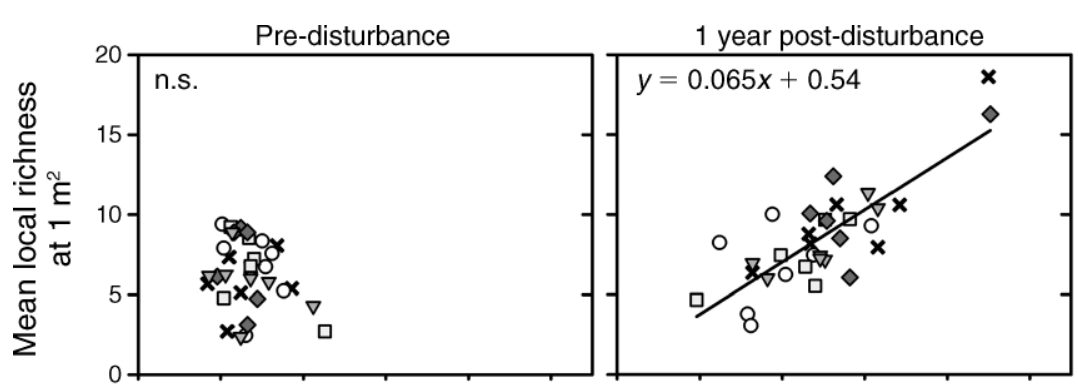

10 years post-disturbance
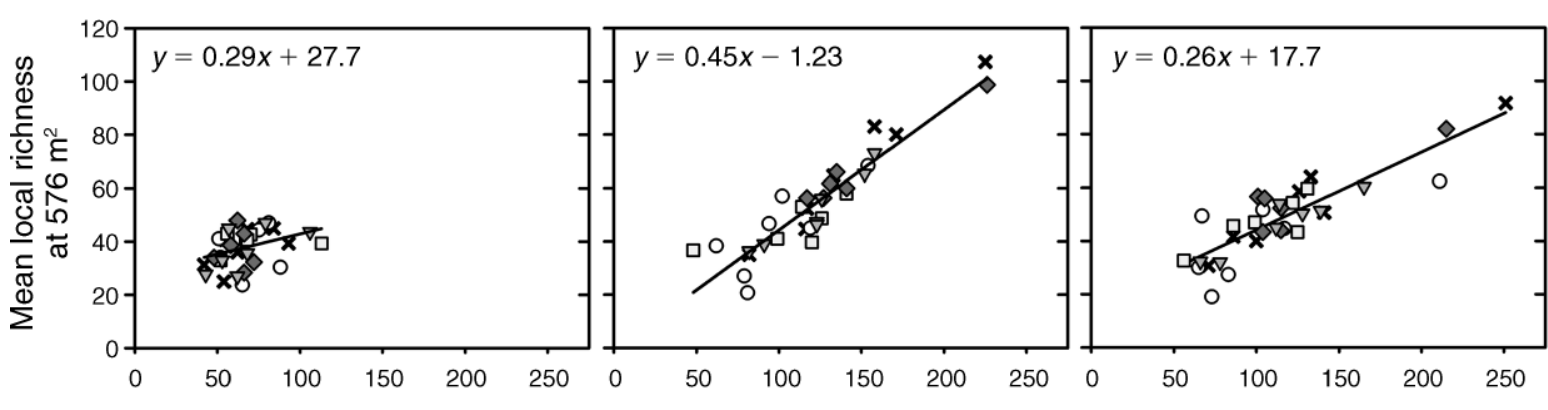

"Regional" species richness at 2 ha

FIG. 3. Local-regional richness relationships across five timber-harvesting disturbance treatments and at three sampling times including pre-disturbance, one year post-disturbance, and 10 years post-disturbance. Control treatments are represented by circles, herbicide treatments are gray squares, shelterwood treatments are gray triangles, leave-tree treatments are dark gray diamonds, and clearcuts are black crosses.

\section{Statistical analysis}

We investigated relationships between species diversity of large experimental units (regional, 2 ha) and the smaller nested plots (local, $576 \mathrm{~m}^{2}$ or $1 \mathrm{~m}^{2}$ ) at the three sampling times (pre-disturbance, one year post-disturbance, and 10 years post-disturbance) using mixed analysis of covariance models (PROC MIXED, SAS 9.1; SAS Institute 2003). First, we modeled how plot and subplot richness were related to 2-ha richness, disturbance treatment, sampling time, and their interactions while accounting for random block effects of site using the entire data set $(N=99 ; 33$ experimental units $\times 3$ sampling times). By controlling for random effects of site, we were able to address some statistical concerns of previous LRR work by accounting for site variability in richness (Srivastava 1999). Separate models were analyzed for $576-\mathrm{m}^{2}$ and $1-\mathrm{m}^{2}$ richness.

If the models detected significant interactions with time, we ran separate analyses within each sampling time across treatments controlling for random site effects $(N$ $=33$ experimental units). To investigate potential species saturation, we ran separate linear and quadratic models and calculated Akaike's information criteria (AIC) for each model. To investigate whether disturbance affected the LRR, we analyzed data within each treatment within each sampling time ( $N=7$ or 6 sites, depending on the treatment) using PROC GLM (SAS 9.1). We used PROC GLM for the within sampling time and treatment analyses to generate least square parameter estimates (slopes) and to compare $R^{2}$ values (PROC MIXED uses maximum likelihood parameter estimates).

We also investigated the effects of disturbance treatment and time on richness at each scale separately using a repeated measures analysis of covariance (PROC MIXED). We included site in the model as a random blocking factor and pre-disturbance richness as a covariate to account for pre-disturbance variability in diversity.

\section{RESUlTS}

When the entire data set was analyzed, local richness at the $1-\mathrm{m}^{2}$ scale was a function of richness at the 2-ha scale and sampling time (Fig. 3; 2-ha richness $\times$ time: $P$ $<0.0001$ ) and treatment (2-ha richness $\times$ treatment: $P=$ $0.04)$. Richness at the $576-\mathrm{m}^{2}$ scale depended on only the interaction between 2-ha richness and time (Fig. 3; $P=$ $0.007)$. Within each sampling time $(N=33$ experimental units), quadratic models accounted for LRR relationships only one year after disturbance, and their fit was never better than linear models (Table 1). Therefore, all subsequent analyses and discussion focus on linear models. Before disturbance, no relationship existed between $1-\mathrm{m}^{2}$ richness and 2-ha richness (Table 1; Fig. 3). However, one year after disturbance, $1-\mathrm{m}^{2}$ richness was a function of 2-ha richness (Fig. 3), but by 10 years after disturbance, the relationship exhibited a shallower slope. The relationship between $576-\mathrm{m}^{2}$ richness and 2ha richness was positive at all three sampling times, but 
TABLE 1. Akaike's information criteria and $P$ values for linear and quadratic functions for localregional richness relationships across disturbance treatments in Appalachian forests $(N=33)$ before canopy disturbance and one year and 10 years after disturbance.

\begin{tabular}{|c|c|c|c|c|c|c|}
\hline \multirow{2}{*}{$\begin{array}{l}\text { Spatial scale } \\
\text { and function }\end{array}$} & \multicolumn{2}{|c|}{ Pre-disturbance } & \multicolumn{2}{|c|}{1 year post-disturbance } & \multicolumn{2}{|c|}{10 years post-disturbance } \\
\hline & AIC & $P$ & AIC & $P$ & AIC & $P$ \\
\hline \multicolumn{7}{|l|}{$1 \mathrm{~m}^{2}$} \\
\hline Linear & 131.1 & 0.97 & 142.9 & $<0.001$ & 133.8 & 0.007 \\
\hline Quadratic & 141.8 & 0.21 & 152.4 & 0.01 & 148.7 & 0.20 \\
\hline \multicolumn{7}{|l|}{$576 \mathrm{~m}^{2}$} \\
\hline Linear & 200.3 & $<0.001$ & 226.0 & $<0.001$ & 226.2 & $<0.001$ \\
\hline Quadratic & 210.1 & 0.61 & 234.5 & 0.03 & 239.8 & 0.83 \\
\hline
\end{tabular}

Note: Data are shown in Fig. 3.

the slope increased immediately after disturbance and became shallower after 10 years, similar to the relationship between $1-\mathrm{m}^{2}$ and 2 -ha richness.

Relationships between local-regional richness within treatments depended on sampling time (Table 2). Before disturbance, no relationship existed between local and regional richness. One year following disturbance, the most disturbed sites tended to exhibit the steepest LRR compared to the less disturbed sites. Ten years following disturbance the only treatment to exhibit a positive LRR was the most disturbed (i.e., clearcut) treatment.

Richness at the regional scale (2-ha experiment unit) differed among treatments $(P<0.001)$ but did not differ with time (Fig. $4 \mathrm{~A} ; P=0.12$ ) or depend on a treatment $\times$ time interaction $(P=0.67)$. Richness at both local scales $\left(576 \mathrm{~m}^{2}\right.$ and $\left.1 \mathrm{~m}^{2}\right)$ depended on disturbance $(P<0.001)$ and time $(P<0.001)$ and only marginally on a treatment $\times$ time interaction $\left(P=0.07\right.$ for $576 \mathrm{~m}^{2}$ and $P=0.06$ for $1 \mathrm{~m}^{2}$ ). Specifically, local richness tended to peak one year after disturbance in the most disturbed treatments and decreased after 10 years (Fig. 4B).

\section{DisCUSSION}

Our work suggests that disturbance mediates localregional richness relationships (LRRs), and LRRs change through time following disturbance. Prior to disturbance, local richness at the smallest spatial scale was not related to regional richness. Immediately following disturbance local richness increased with regional richness, and the strength of the relationship depended on disturbance intensity. Specifically, local richness depended strongly on regional richness in the most disturbed plots. Consistent with our predictions, the slopes of LRRs changed following disturbance and through time, and after 10 years LRRs appear to be returning to pre-disturbance conditions. These patterns suggest that local communities may become unsaturated after disturbances, when colonization of species overrides local interactions as an important process influencing local diversity (sensu $\mathrm{He}$ et al. 2005). As the community reorganizes following disturbance, strong interactions reduce local diversity and cause the slopes of LRRs to decline. Therefore, our results suggest that the slope of LRRs at different times may provide another important method of understanding the relative role of local and regional processes on the structure and dynamics of ecological communities.

We predicted LRRs would be asymptotic before disturbance and again 10 years following disturbance reflecting the importance of species interactions or

TABLE 2. Slope, $R^{2}$, and $P$ values for within-treatment regressions between species richness measured in 2-ha experimental units and mean species richness measured within either $181-\mathrm{m}^{2}$ subplots or three $576-\mathrm{m}^{2}$ plots.

\begin{tabular}{|c|c|c|c|c|c|c|c|c|c|}
\hline \multirow[b]{2}{*}{ Spatial scale and function } & \multicolumn{3}{|c|}{ Pre-disturbance } & \multicolumn{3}{|c|}{1 year post-disturbance } & \multicolumn{3}{|c|}{10 years post-disturbance } \\
\hline & Slope & $R^{2}$ & $P$ & Slope & $R^{2}$ & $P$ & Slope & $R^{2}$ & $P$ \\
\hline \multicolumn{10}{|l|}{$1 \mathrm{~m}^{2}$} \\
\hline Control & -0.05 & 0.09 & 0.51 & 0.04 & 0.18 & 0.34 & 0.004 & 0.01 & 0.8 \\
\hline Herbicide & -0.07 & 0.44 & 0.15 & 0.05 & 0.56 & 0.09 & 0.05 & 0.41 & 0.17 \\
\hline Shelterwood & -0.03 & 0.13 & 0.43 & 0.06 & 0.72 & 0.02 & 0.01 & 0.16 & 0.36 \\
\hline Leave tree & -0.07 & 0.06 & 0.64 & 0.06 & 0.52 & 0.10 & 0.04 & 0.49 & 0.12 \\
\hline Clearcut & 0.03 & 0.09 & 0.50 & 0.08 & 0.78 & 0.009 & 0.04 & 0.87 & 0.002 \\
\hline \multicolumn{10}{|l|}{$576 \mathrm{~m}^{2}$} \\
\hline Control & 0.11 & 0.03 & 0.71 & 0.42 & 0.61 & 0.04 & 0.21 & 0.51 & 0.07 \\
\hline Herbicide & 0.02 & 0.02 & 0.80 & 0.19 & 0.55 & 0.09 & 0.27 & 0.68 & 0.04 \\
\hline Shelterwood & 0.24 & 0.37 & 0.15 & 0.46 & 0.91 & 0.0008 & 0.29 & 0.89 & 0.002 \\
\hline Leave tree & -0.06 & 0.01 & 0.89 & 0.39 & 0.97 & 0.0005 & 0.28 & 0.78 & 0.02 \\
\hline Clearcut & 0.24 & 0.36 & 0.15 & 0.53 & 0.96 & 0.0001 & 0.33 & 0.92 & 0.0007 \\
\hline
\end{tabular}

Note: $N=7$ for all treatments except herbicide and shelterwood, where $N=6$. 

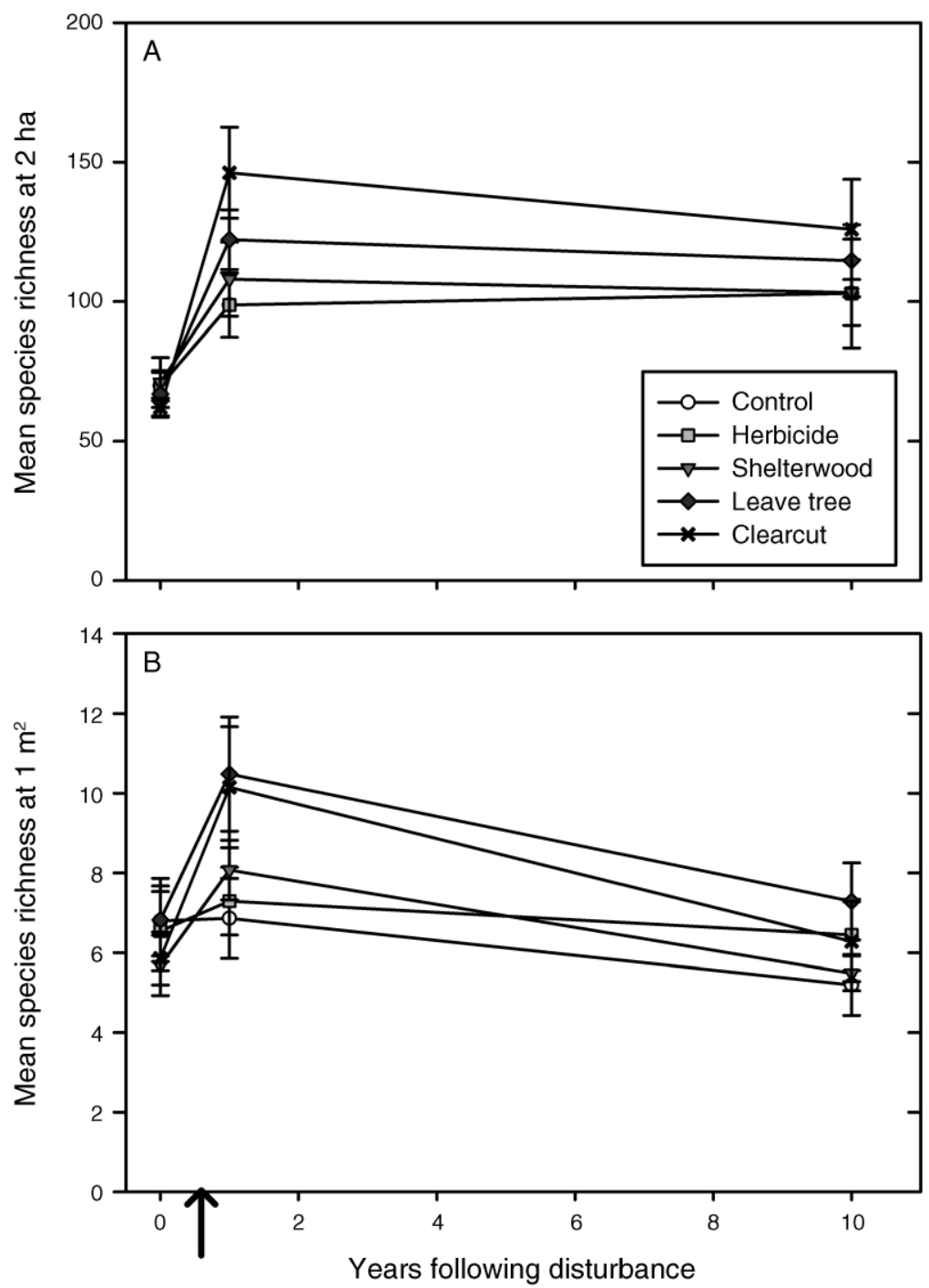

FIG. 4. Richness at (A) regional (2-ha) and (B) local $\left(1-\mathrm{m}^{2}\right)$ scales within each treatment and through time to emphasize the maintenance of diversity at regional scales but a decline in diversity at local scales during canopy development and recovery following disturbance. The arrow indicates time of disturbance treatment application. See Results for treatment and time effects. Richness of treatments at the $576-\mathrm{m}^{2}$ scale is not shown because of similarities in patterns between $576-\mathrm{m}^{2}$ and $1-\mathrm{m}^{2} \mathrm{scales}$.

canopy shading in forests. However, we found little evidence of a saturating LRR even at the smallest spatial scale $\left(1 \mathrm{~m}^{2}\right)$ where saturation is expected either because of sampling issues (Loreau 2000) or competitive exclusion (Huston 1999). Several ecologists have pointed out the difficulty in determining linear vs. saturating functions (Srivastava 1999, Hillebrand and Blenckner 2002). It is possible that a saturating LRR existed before disturbance, but that the lower limits of richness at our regional scale prevented detection of such a pattern.

As we predicted, disturbance increased diversity at all spatial scales, which in turn led to positive LRRs after disturbance. The change in relationship between local and regional diversity after disturbance was related to colonization of species after removing biological or environmental resistance to shade intolerant species (Belote et al. 2008). In temperate forests, dominant overstory tree species control understory plant species diversity (e.g., Gilliam and Roberts 2003). In contrast to our results, Collins et al. (2002), working in a tallgrass prairie, showed that LRRs were stronger (i.e., more variance in the relationship explained) in less disturbed communities than in those experiencing fire or bison grazing. In our system, the control exerted by a closed canopy forest on the understory plant community may be reduced or temporarily eliminated by timber harvesting. Colonization of new species via germination of dormant seeds and post-disturbance seed dispersal 


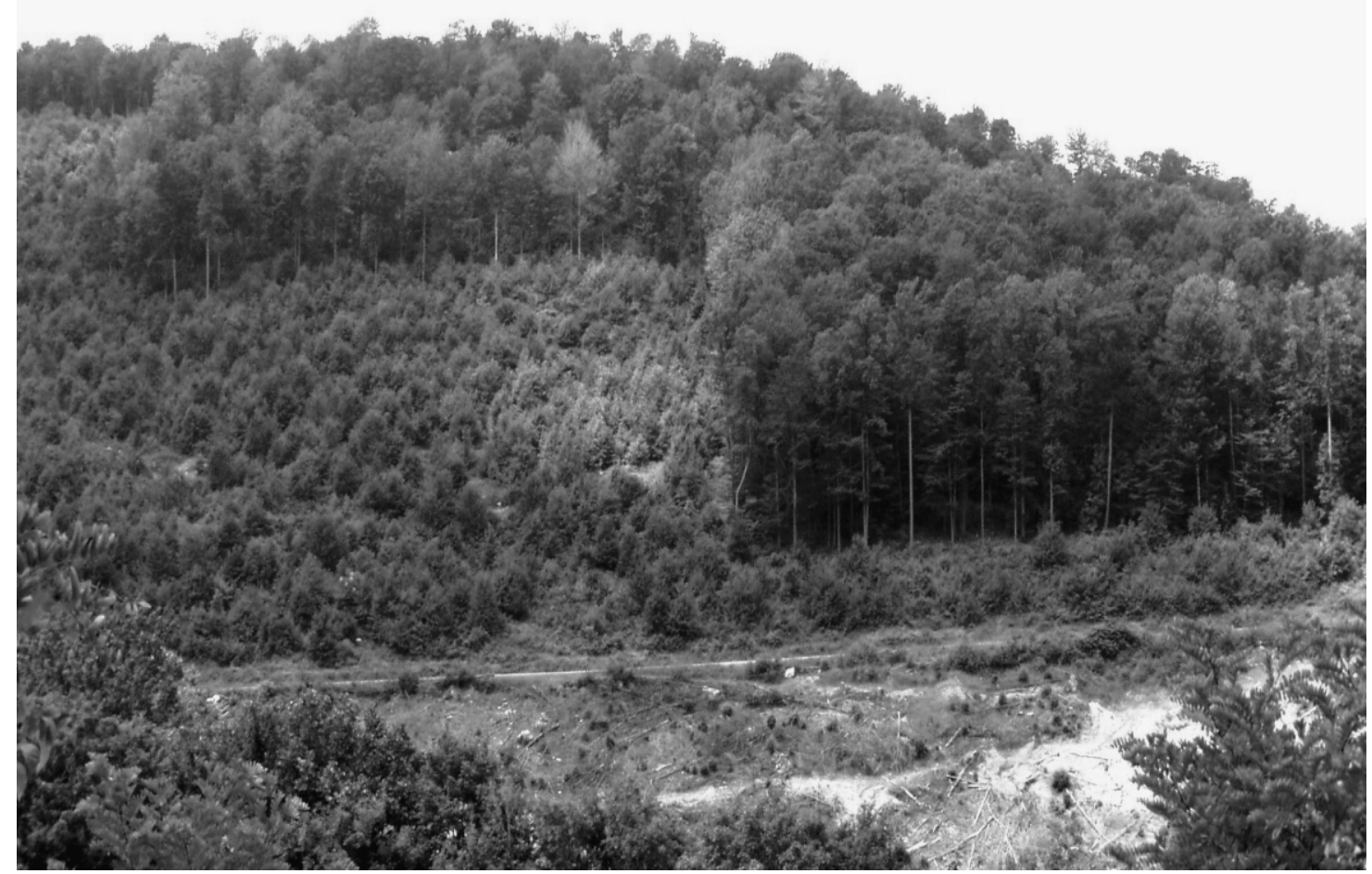

Plate 1. Disturbance mediates the relationship between local and regional plant diversity in Appalachian forests. Disturbance treatments were applied to 2-ha experimental units and represented a gradient from uncut control to clearcut tree harvest. Pictured on the left is a clearcut treatment several years post-disturbance; on the right is an uncut control treatment. Photo credit: Tom Fox.

subsequently becomes a strong influence on local species diversity, but after 10 years of forest development, the effects of the canopy once again control diversity. Thus, our results and those from studies of different plant communities suggest that investigating temporal patterns of LRRs may be an important tool to understanding local controls of species diversity.

Our empirical results generally support previous attempts to model local-regional richness relationships through time during community assembly (Mouquet et al. 2003). Mouquet et al. (2003) predicted that the slope of the LRR should increase through time until the community reaches equilibrium at which time the LRR slope would decrease to zero through competitive exclusion. Our results differ slightly from Mouquet et al. (2003) in that our LRR slopes were steepest immediately after disturbance, whereas their modeled LRR slopes became steepest at a relatively later stage after disturbance. These differences between studies may be due to the timing of colonists which increased for multiple years in Mouquet et al.'s model, but apparently peaked one year after disturbance in our system (although the exact shape of the how local richness varied through time is unknown because we resampled only one and ten years post-disturbance). In an empirical study on microarthropods occupying moss beds, Starzomski et al. (2008) found that local richness did not depend on regional richness during any time of community assembly. Thus, it remains to be seen how, or whether, time since disturbance might affect LRRs across other communities.

LRRs are only patterns, yet they are used to infer underlying community processes operating at either local or regional scales (Huston 1999, Harrison and Cornell 2008). In our case, the underlying processes included disturbance, colonization, and post-disturbance shading of the understory by tree canopy closure. Moreover, disturbance was both a regional and local event causing richness to increase at all scales. After 10 years, richness at the largest ("regional") spatial scale remained relatively stable, while decreasing at the smaller scales. Environmental heterogeneity at the 2-ha experimental units allowed for diversity following disturbance to be maintained in patches of high light, 
which in this study system included skid trails used by logging machinery. However, at the smaller spatial scales, plots and subplot typically occurred outside of these skid trails. Thus, many initial colonizers did not persist as the canopy closed (Belote 2008), presumably because light level decreased below their minimum maintenance level. Areas where diversity of shade intolerant species was maintained at the 2-ha spatial scale even 10 years after disturbance are an example of local diversity influencing regional diversity. Canopy closure thus decreases diversity at small scales representative of a maturing forest, but heterogeneity caused by patches sampled across larger scales allows diversity of colonizers to be maintained after 10 years of canopy development (sensu Huston 1999).

In sum, these results suggest that disturbance mediates the relative influence of local processes vs. regional species pools on local community diversity. While the scale at which we define "regional" species pools is much smaller than typically considered, our results do suggest that disturbance may set the stage for strong influences by the regional species pool. As time since disturbance increases, local controls on community assembly decouple the relationships between regional and local diversity. Additional studies are needed to examine whether these patterns and hypothesized mechanisms differ among vegetation types, biomes, or types of disturbance (Huston 1999). However, direct comparisons between this and other studies may be difficult because experimental designs, plot sizes, and definitions of "local" and "regional" vary among studies (Srivastava 1999).

\section{ACKNOWLEDGMENTS}

David Wm. Smith and Shep Zedaker initiated the project and directed experimental design and initial data collection. David Loftis provided funding for project initiation through the USFS Ecosystem Management Program. David Wm. Smith and Carola Haas expanded the study under USDA-NRI grant \#9503196. Eric Sokol, Tom Wieboldt, Tom Fox, and Erik Nilsen provided guidance throughout experimental setup, data collection, or manuscript preparation. Aaron Teets, Anna Morkeski, Sharon Hood, Bryan Wender, Meral Jackson, and others helped collect data. USDA-NRI grant \#2005-3510115363 funded data analysis and manuscript preparation.

\section{Literature Cited}

Belote, R. T. 2008. Diversity, invasibility, and stability of Appalachian forests across an experimental disturbance gradient. Dissertation. Virginia Tech, Blacksburg, Virginia, USA.

Belote, R. T., R. H. Jones, S. M. Hood, and B. W. Wender. 2008. Diversity-invasibility across an experimental disturbance gradient in Appalachian forests. Ecology 89:183-192.
Caley, M. J., and D. Schluter. 1997. The relationships between local and regional diversity. Ecology 78:70-80.

Collins, S. L., S. M. Glenn, and J. M. Briggs. 2002. Effects of local and regional processes on plant species richness in tallgrass prairie. Oikos 99:571-579.

Cornell, H. V., and J. H. Lawton. 1992. Species interactions, local and regional processes, and limits to the richness of ecological communities: theoretical perspectives. Journal of Animal Ecology 61:1-12.

Foster, D. R., D. H. Knight, and J. F. Franklin. 1998. Landscape patterns and legacies resulting from large infrequent forest disturbances. Ecosystems 1:497-510.

Gilliam, F. S., and M. R. Roberts. 2003. Interactions between the herbaceous layer and overstory canopy of eastern forests. Pages 198-223 in F. S. Gilliam and M. R. Roberts, editors. The herbaceous layer in forests of eastern North America. Oxford University Press, New York, New York, USA.

Harrison, S., and H. Cornell. 2008. Toward a better understanding of the regional causes of local community richness. Ecology Letters 11:1-11.

He, F., K. J. Gaston, E. F. Connor, and D. S. Srivastava. 2005. The local-regional relationship: immigration, extinction, and scale. Ecology 86:360-365.

Hillebrand, H. 2005. Regressions of local on regional diversity do not reflect the importance of local interactions or saturation of local diversity. Oikos 110:195-198.

Hillebrand, H., and T. Blenckner. 2002. Regional and local impact on species diversity: from pattern to processes. Oecologia 132:479-491.

Hood, S. M. 2001. Vegetation responses to seven silvicultural treatments in the southern Appalachians one year after harvesting. Thesis. Virginia Tech, Blacksburg, Virginia, USA.

Huston, M. A. 1999. Local processes and regional patterns: appropriate scales for understanding variation in the diversity of plants and animals. Oikos 86:393-401.

Loreau, M. 2000. Are communities saturated? On the relationship between $\alpha, \beta$, and $\gamma$ diversity. Ecology Letters 3:73-76.

Mouquet, N., P. Munguia, J. M. Kneitel, and T. E. Miller. 2003. Community assembly time and the relationship between local and regional species richness. Oikos 103:618626.

SAS Institute. 2003. SAS 9. 1. SAS Institute, Inc., Cary, North Carolina, USA.

Shurin, J., and D. S. Srivastava. 2005. New perspectives on local and regional diversity: beyond saturation. Pages 146169 in M. Holyoak, M. Leibold, and R. Holt, editors. Metacommunities: spatial dynamics and ecological communities. University of Chicago Press, Chicago, Illinois, USA.

Srivastava, D. 1999. Using local-regional richness plots to test for species saturation: pitfalls and potentials. Journal of Animal Ecology 68:1-16.

Starzomski, B. M., R. L. Parker, and D. S. Srivastava. 2008. On the relationship between regional and local species richness: a test of saturation theory. Ecology 89:1921-1930.

Stohlgren, T. J., D. T. Barnett, C. S. Jarnevich, C. Flather, and J. Kartesz. 2008. The myth of plant species saturation. Ecology Letters 11:1-10.

\section{APPENDIX}

Richness of vascular plant species at three spatial scales sampled at three time periods across a disturbance gradient replicated at seven sites in the southern Appalachian Mountains, USA (Ecological Archives E090-209-A1). 